\title{
Myocardial Infarction, Unstable Angina, and White Thrombi: Time to Move Forward?
}

Giuseppe Lippi, MD ${ }^{1}$ Emmanuel J. Favaloro, PhD, FFSc (RCPA) ${ }^{2}$
Address for correspondence Emmanuel J. Favaloro, PhD, FFSc (RCPA), Department of Clinical and Laboratory Haematology, Sydney Centres for Thrombosis and Haemostasis, Institute of Clinical Pathology and Medical Research, NSW Health Pathology, Westmead Hospital, Cnr Hawkesbury Road and Darcy Road, Westmead, New South Wales 2145, Australia (e-mail: emmanuel.favaloro@health.nsw.gov.au).

Semin Thromb Hemost 2019;45:115-116.

We are thankful to Silvia Hoirisch-Clapauch for her comments ${ }^{1}$ on our previous article on venous and arterial thromboses, ${ }^{2}$ which now give us the opportunity to clarify some important aspects in both papers. In particular, Dr. Hoirisch-Clapauch highlights that white thrombi are observed in the vast majority of patients with unstable angina (UA), whereas they are not seen in other patients with myocardial infarction (MI). However, this is not a clearcut concept, for at least two reasons.

The current definition of acute myocardial infarct (AMI) is based either on its pathogenesis (thus distinguishing 5 different type of AMI) or on the presence of significant alterations of the ST tract with an electrocardiogram (ECG). ${ }^{3}$ This latter aspect has allowed the differentiation of AMI into ST-elevation MI (STEMI) and non-STEMI (NSTEMI). Notably, the old concepts of "stable" and "unstable" angina are largely questionable according to our current understanding of AMI. ${ }^{4}$ This paradigm shift was introduced nearly 10 years ago, after the development of a new generation of immunoassays for measuring cardiac troponins. These have been conventionally called "high-sensitivity" (HS) since their analytical sensitivity has been vastly improved to allow measuring 10 - to 100 -fold lower cardiac troponin values than with previous techniques, even in healthy subjects with no clinical (or radiological) signs of myocardial injury. ${ }^{5}$ In a foremost editorial published in the journal Circulation, the two godfathers of modern cardiology, Braunwald and Morrow, have concluded that the introduction of the new cardiac troponin HS immunoassays has allowed the reclassification of the vast majority (if not all) of patients with "previously defined" UA as having an NSTEMI. ${ }^{6}$ The word "requiem," as referring to UA in their editorial title, was not used casually. This concept has straightforward significance when applied to studies published before the advent of the cardiac tropo- nin HS immunoassays, such as that published in the New England Journal of Medicine in 1992, ${ }^{7}$ and cited by Dr. Hoirisch-Clapauch in her letter, ${ }^{1}$ since it is likely misleading to translate these previous findings to the current and universally accepted definition of acute coronary syndrome. Therefore, continued use of the term UA may contribute to generate confusion since it scarcely reflects the pathophysiology of coronary thrombosis and may also "mean rather different things to different people." 6

The notion that the so-called white thrombi may be absent in patients with some forms of acute coronary syndrome (probably referring to STEMI, given that Dr. Hoirisch-Clapauch appears to have overlooked the recent progress in the definition of AMI) conflicts with other more recent findings. Again, the relevant article cited by Dr. Hoirisch-Clapauch ${ }^{1}$ was published in 1992 (i.e., more than 25 years ago). ${ }^{7}$ Since then, much more sophisticated techniques have been used to obtain and analyze intracoronary thrombi, and many ensuing studies have all been concordant to conclude that fibrin and platelets are the leading components of thrombi found in patients with an acute coronary syndrome. ${ }^{8-10}$ In a recent study, Uchida et al also showed that white thrombi could be detected in as many as $36 \%$ of patients with NSTEMI and $21 \%$ of those with STEMI, respectively. ${ }^{11}$ Therefore, asserting that white thrombi may be absent in patients with acute coronary syndrome appears to be in error, when referring to either NSTEMI or STEMI.

As regards the additional concepts expressed by Dr. Hoirisch-Clapauch on the pathogenesis of $\mathrm{UA},{ }^{1}$ we have previously discussed that this notion is so much marginalized now that it should probably no longer be used. The older bibliography referenced by Dr. Hoirisch-Clapauch (the most recent article being published in 2005) is probably no published online June 4, 2018
Issue Theme Editorial Compilation VI; Guest Editors: Emmanuel J. Favaloro, PhD, FFSc (RCPA), and Giuseppe Lippi, MD.
Copyright $\odot 2019$ by Thieme Medical Publishers, Inc., 333 Seventh Avenue, New York, NY 10001, USA. Tel: +1(212) 584-4662.
DOI https://doi.org/ 10.1055/s-0038-1657781. ISSN 0094-6176. 
longer relevant in light of the current pathophysiology of acute coronary syndrome, now centered on the use of cardiac troponin HS immunoassays.

Other than the preceding responses, related to earlier parts of the correspondence, we have no specific comments on the role of anxiety and depression in the pathogenesis of acute coronary syndrome. A comprehensive discussion about the interplay between stress and hemostasis has already been published within Seminars in Thrombosis and Hemostasis, ${ }^{12}$ and we also provided recent updates on the association between cardiovascular disease and mental depression in one of our other articles. ${ }^{13}$ It is thus substantially likely that both these conditions (anxiety and depression) may represent putative triggers, or contributing factors, of AMI, although their relationship with the nature and structure of coronary thrombi is currently lacking any reliable scientific evidence.

\section{Conflict of Interest}

None

\section{References}

1 Hoirisch-Clapauch S. Comment on "Venous and Arterial Thromboses: Two Sides of the Same Coin?" Semin Thromb Hemost 2019; 45(01):113-114

2 Lippi G, Favaloro EJ. Venous and arterial thromboses: two sides of the same coin? Semin Thromb Hemost 2017( e-pub ahead of print). Doi: 10.1055/s-0037-1607202
3 Cervellin G, Mattiuzzi C, Bovo C, Lippi G. Diagnostic algorithms for acute coronary syndrome-is one better than another? Ann Transl Med 2016;4(10):193

4 Cervellin G, Lippi G. Of MIs and men-a historical perspective on the diagnostics of acute myocardial infarction. Semin Thromb Hemost 2014;40(05):535-543

5 Lippi G, Cervellin G. High-sensitivity cardiac troponin in the emergency department: The perfect storm? Int J Cardiol 2017; 234:113

6 Braunwald E, Morrow DA. Unstable angina: is it time for a requiem? Circulation 2013;127(24):2452-2457

7 Mizuno K, Satomura K, Miyamoto A, et al. Angioscopic evaluation of coronary-artery thrombi in acute coronary syndromes. N Engl J Med 1992;326(05):287-291

8 Silvain J, Collet JP, Nagaswami C, et al. Composition of coronary thrombus in acute myocardial infarction. J Am Coll Cardiol 2011; 57(12):1359-1367

9 Sadowski M, Ząbczyk M, Undas A. Coronary thrombus composition: links with inflammation, platelet and endothelial markers. Atherosclerosis 2014;237(02):555-561

10 Zalewski J, Bogaert J, Sadowski M, et al. Plasma fibrin clot phenotype independently affects intracoronary thrombus ultrastructure in patients with acute myocardial infarction. Thromb Haemost 2015;113(06):1258-1269

11 Uchida Y, Uchida Y, Sakurai T, Kanai M, Shirai S, Morita T. Characterization of coronary fibrin thrombus in patients with acute coronary syndrome using dye-staining angioscopy. Arterioscler Thromb Vasc Biol 2011;31(06):1452-1460

12 Austin AW, Wissmann T, von Kanel R. Stress and hemostasis: an update. Semin Thromb Hemost 2013;39(08):902-912

13 Lippi G, Montagnana M, Favaloro EJ, Franchini M. Mental depression and cardiovascular disease: a multifaceted, bidirectional association. Semin Thromb Hemost 2009;35(03):325-336 